\title{
Investigation and characterization by TG/DTG-DTA and DSC of the fusion of Riboflavin, and its interaction with the antibiotic norfloxacin in the screening of cocrystal
}

\author{
Laura Teófilo Ferreira $^{1} \cdot$ Rafael Turra Alarcon ${ }^{1} \cdot$ Glauco Lini Perpétuo $^{2} \cdot$ Gilbert Bannach $^{1}$
}

Received: 15 May 2018/Accepted: 19 August 2018/Published online: 24 August 2018

(C) Akadémiai Kiadó, Budapest, Hungary 2018

\begin{abstract}
This work synthesized and characterized the NOR-RIB 1:1 (mol-mol) cocrystal. During a study of the reagents, Riboflavin (RIB) melted at $304{ }^{\circ} \mathrm{C}$, which is different from the temperature previously reported in the literature $\left(280-290{ }^{\circ} \mathrm{C}\right)$; therefore, this compound was characterized individually. Subsequently, the cocrystal was synthesized with the active pharmaceutical ingredient (API) norfloxacin (NOR) with the RIB coformer, and the mechanochemical synthesis route was adopted. NOR, RIB, and the cocrystal were characterized by thermogravimetry-differential thermal analysis (TG-DTA), differential scanning calorimetry (DSC), DSC coupled to a microscope (photo-DSC), mid-infrared spectroscopy (MIR), and powder X-ray diffraction. The results of thermal analysis showed that the RIB starts decomposition process $\left(260{ }^{\circ} \mathrm{C}\right)$ and then melts $\left(304{ }^{\circ} \mathrm{C}\right)$. The MIR found that beginning at $295{ }^{\circ} \mathrm{C}$, the RIB passes into the form of a decomposition intermediate; therefore, the melting point observed in the DSC curve is related to this decomposition material. The cocrystal presented thermal stability $\left(200{ }^{\circ} \mathrm{C}\right)$ lower than the API $\left(235{ }^{\circ} \mathrm{C}\right)$ and the coformer $\left(260^{\circ} \mathrm{C}\right)$. The DSC curve did not contain a melting peak. The bands at $1726 \mathrm{~cm}^{-1}$ ( $\mathrm{C}=\mathrm{O}$ of the carboxylic acid) for the NOR, and the band at $3326 \mathrm{~cm}^{-1}$ (stretch $\mathrm{O}-\mathrm{H}$ ), among others, were not visible for the cocrystal in the MIR spectrum, indicating interactions in these regions. The X-ray diffractograms showed a new diffraction pattern, which proved the obtainment of a new phase and cocrystal formation.
\end{abstract}

Keywords Cocrystal $\cdot$ Mechanochemistry $\cdot$ Norfloxacin $\cdot$ Riboflavin $\cdot$ TG-DTA $\cdot$ Photo-DSC

\section{Introduction}

The development of solid oral dosage forms has been of great interest in the pharmaceutical industry, having lower manufacturing costs and greater stability; however, these forms depend on their release, solubility, and permeability across the membranes of the gastrointestinal tract [1-3].

Electronic supplementary material The online version of this article (https://doi.org/10.1007/s10973-018-7696-7) contains supplementary material, which is available to authorized users.

Laura Teófilo Ferreira

gilbert.bannach@unesp.br

1 School of Sciences, Chemistry Department, UNESP - São Paulo State University, Bauru, SP, Brazil

2 Engineering College of Bauru, UNESP - São Paulo State University, Bauru, SP, Brazil
According to the biopharmaceutical classification system (BCS), class IV drugs are low solubility and low permeability compounds; consequently, these drugs encounter problems to reach desirable therapeutic blood levels. In this way, the solubility of an active principle is the main target of improvements, since it has a direct relationship with the improvement in its bioavailability $[4,5]$. Cocrystals are an interesting opportunity to modify the properties of an active pharmaceutical ingredients (API), such as processability, stability, solubility, and bioavailability [6]. Breakage or formation of covalent bonds is not required to cocrystal formation [7].

A cocrystal can be defined as a multicomponent crystalline solid bound by non-covalent interactions, mainly hydrogen interactions. Its aim is to improve the physicochemical properties of organic compounds, such as medications [8-10]. The mechanochemical method, solventassisted grinding, consists of grinding the components in the solid state with a few microliters of solvent, which acts 
on the kinetics of the interaction reaction between the reactants [11]. This method is widely used due to better homogeneity, obtaining a single crystalline phase in the synthesis product, and uses fewer reagents compared to the solvent evaporation crystallization method [8, 12, 13].

Norfloxacin (NOR), 1-ethyl-6-fluoro-4-oxo-7-piperazin1-yl-1H-quinoline-3-carboxylic acid, is a class 4 antibiotic according to the biopharmaceutical classification system (BCS) with low permeability in biomembranes and low solubility in water. It is used to treat urinary tract infections [14]. In this work, NOR was the API with the intention of obtaining a cocrystal of this drug. Riboflavin (RIB), 7,8dimethyl-10-[(2S, 3S, 4R)-2,3,4,5-tetrahydroxypentyl]benzo[g]pteridine-2,4-dione, is a water-soluble vitamin [15], used in this work as a coformer. According to the literature, RIB melts at approximately $280{ }^{\circ} \mathrm{C}$ followed by decomposition [15-17], or simultaneously melts and decomposes at $290{ }^{\circ} \mathrm{C}$ [18].

Thermogravimetry-differential thermal analysis (TGDTA) and differential scanning calorimetry (DSC) are very relevant thermoanalytical techniques to analyze drugs and cocrystals. Alterations in the thermal stability, changes in the decomposition events, and the melting point of the synthesis product indicate interaction between the reagents. Changes in melting point and other thermal events indicate the formation of a new product [13]. Powder X-ray diffraction (PRXD) provides information on the sample phase, allowing differentiation of a physical mixture of a cocrystal, because a cocrystal occurs by the formation of a new crystalline phase, resulting in a new diffraction pattern. In the physical mixtures, only a physical mixture of the reactants results in the overlap of the diffractograms. Mid-infrared spectroscopy (MIR) indicates the functional groups of interaction between the API and the coformer. The aim of this work is to elucidate the thermal behavior of Riboflavin as well as the characterization of its cocrystal with norfloxacin by LAG (liquid-assisted grinding).

\section{Materials and methods}

\section{Mechanochemical study of reagents}

To verify whether the mechanochemical method used for cocrystal synthesis could cause polymorphic transition to pure NOR or RIB, $0.5004 \mathrm{~g}$ of NOR and $0.5006 \mathrm{~g}$ of RIB were separately milled at $30 \mathrm{~Hz}$ for $30 \mathrm{~min}$ in a ball mill, with one stainless steel ball for each sample.

\section{Synthesis of the cocrystal}

The reagents, norfloxacin (purity $\geq 98 \%$ ), Riboflavin form A (purity $\geq 98 \%$ ), and analytical grade chloroform were purchased from Sigma-Aldrich and used without purification. The synthesis was done by mechanized grinding, in Retsch MM 400 ball mill, assisted by $15 \mu \mathrm{L}$ of the chloroform solvent, in a molar ratio of 1:1 (API/coformer) at a frequency of $30 \mathrm{~Hz}$, for $30 \mathrm{~min}$. The mass used was of $0.3002 \mathrm{~g}$ of the NOR API $\left(9.94 \times 10^{-4} \mathrm{~mol}\right)$ and $0.3536 \mathrm{~g}$ of the RIB coformer $\left(9.40 \times 10^{-4} \mathrm{~mol}\right)$.

\section{Powder X-ray diffractograms (PXRD)}

The PXRD was obtained with the Rigaku Diffometer MiniFlex 600 model, using copper tube, submitted to $20 \mathrm{kV}$, current of $20 \mathrm{~mA}, \mathrm{Cu} \kappa \alpha, \lambda=1.54056 \AA$. The samples were placed in a glass support and exposed to radiation $\left(3^{\circ} \leq 2 \theta \leq 50^{\circ}\right)$.

\section{Thermogravimetry-differential thermal analysis (TG-DTA)}

The TG/DTG-DTA curves were obtained by the Netzsch model STA $449 \mathrm{~F} 3$, using a sample mass close to $7.0 \mathrm{mg}$ and a heating rate of $10{ }^{\circ} \mathrm{C} \mathrm{min}{ }^{-1}$ in dry air atmosphere with a flow of $50 \mathrm{~mL} \mathrm{~min}{ }^{-1}$ and temperature range of 30-800 ${ }^{\circ} \mathrm{C}$.

\section{Exploratory differential calorimetry and photo- DSC}

The DSC curves and images were obtained with the Mettler-Toledo model DSC 1 Stare System coupled to a SC 30 digital camera, which incorporates a 3.3 megapixel CMOS sensor, Navitar 1-6232D mechanical optical subset with $6.5 \times$ zoom. Sample masses of approximately $2.0 \mathrm{mg}$ and heating ratio of $10{ }^{\circ} \mathrm{C} \mathrm{min}^{-1}$ were used in a dry air atmosphere with a flow of $50 \mathrm{~mL} \mathrm{m^{-1 }}, 40 \mu \mathrm{L}$ aluminum crucible, with perforated lid and crucible of open $\alpha$-alumina, $30 \mu \mathrm{L}$ (photo-DSC) and heating intervals of $30-330{ }^{\circ} \mathrm{C}$ for RIB and $30-240{ }^{\circ} \mathrm{C}$ for NOR and cocrystal. A complementary study was done with the RIB, which was heated to $295{ }^{\circ} \mathrm{C}$ and maintained in isotherm at this temperature for $3 \mathrm{~min}$.

\section{Mid-infrared spectroscopy (MIR)}

MIR spectra were obtained using Bruker's Vertex 70 spectrometer, which were obtained by means of the attenuated reflectance (ATR) method, with a scanning range from $500 \mathrm{~cm}^{-1}$ to $4000 \mathrm{~cm}^{-1}$ (resolution of $4 \mathrm{~cm}^{-1}$ ) in a diamond crystal as carrier. 


\section{Results and discussion}

\section{TG-DTA}

The TG/DTG-DTA curves indicate that the NOR is stable up to $235^{\circ} \mathrm{C}$ (Fig. 1a) and presents four steps of mass loss. The first step is related to water evaporation and the second step to organic matter degradation. The third and fourth steps of mass loss are associated with the decomposition and oxidation of carbonaceous material (related to exothermic events in DTA curve). The endothermic peak at $213{ }^{\circ} \mathrm{C}$ in the DTA curve is associated with melting of the compound.

The TG/DTG-DTA curves show that the RIB is stable up to $261{ }^{\circ} \mathrm{C}$ (Fig. 1b) with three steps of mass loss. The first and second steps are overlapping and consecutive events, which are considered a complex thermal decomposition, relative to the degradation of the compound. The third mass loss is associated with the decomposition and oxidation of carbonaceous material. The endothermic peak at $298{ }^{\circ} \mathrm{C}$ on the DTA curve is associated with melting of the compound.
Fig. 1 TG/DTG-DTA curves of a NOR, b RIB, and c cocrystal

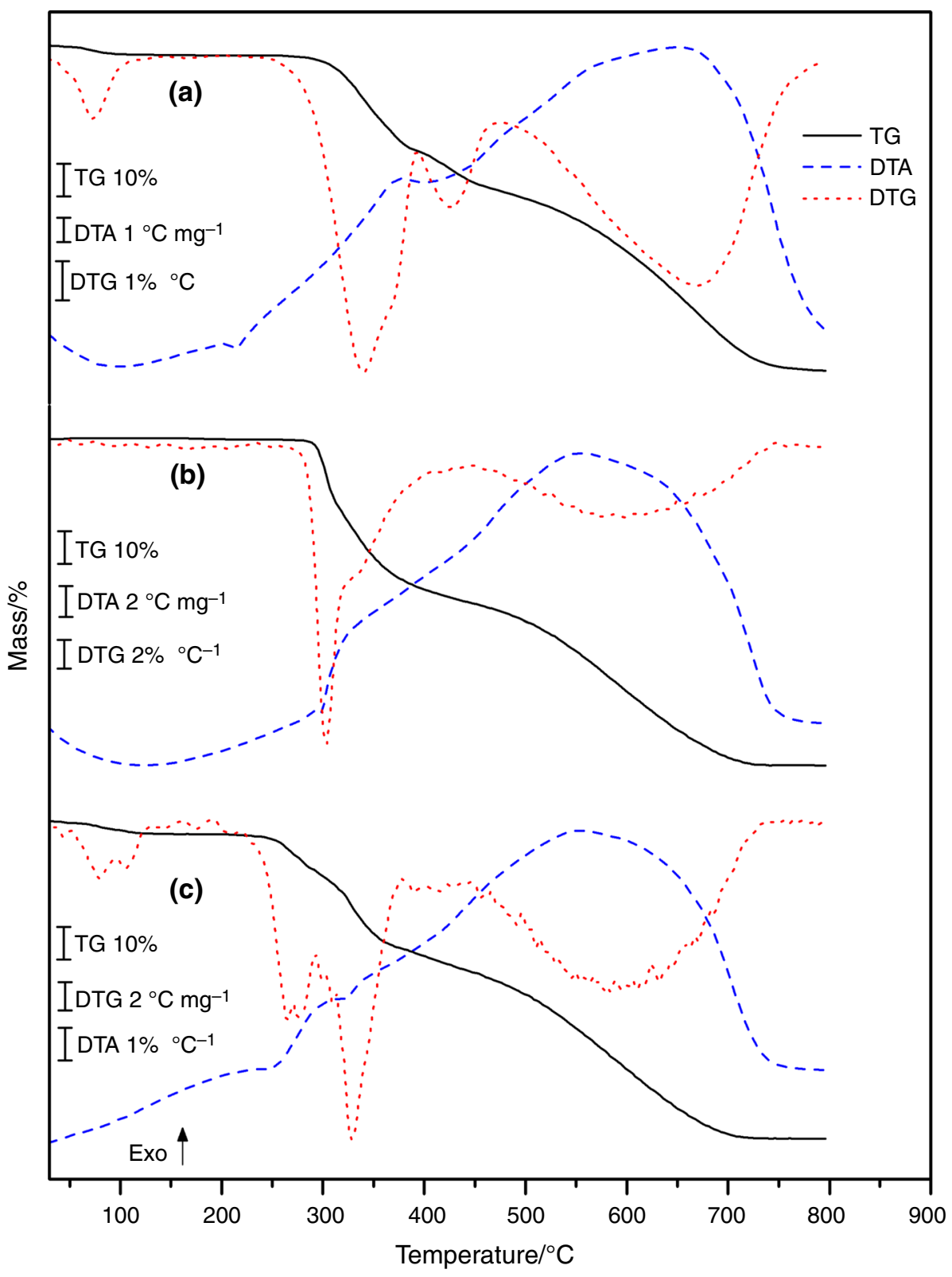


The TG/DTG-DTA curves of the cocrystal (Fig. 1c) showed that the compound is stable up to $200{ }^{\circ} \mathrm{C}$ and has four steps of mass loss. The first one referring to the loss of volatiles (water/chloroform), and the second step of mass loss refers to the degradation of the compound followed by the third step. Finally, the fourth step of mass loss is associated with the decomposition and oxidation of carbonaceous material.

No residue was observed at the end of the analyses. The temperature ranges, mass loss $(\Delta m)$, and peak temperature $\left(T_{\mathrm{P}}\right)$ observed at each step in the TG/DTG-DTA curves of NOR, RIB, and NOR-RIB 1:1 are illustrated in Table 1.

TG/DTG-DTA techniques are not widely used in the study and characterization of cocrystals in others works, however, these techniques are essential to determine the thermal stability of these compounds, the presence of unbound or adsorbed water and solvent, and may indicate the interaction between the reagents by interpretation of the thermoanalytical curves. They are necessary for better interpretation of the DSC curves. Changes in the thermal stability of the mechanochemical synthesis product indicate interaction between API and coformer [19]. The cocrystal had a thermal stability $\left(200^{\circ} \mathrm{C}\right)$ different from the API $\left(235^{\circ} \mathrm{C}\right)$ and the coformer $\left(261^{\circ} \mathrm{C}\right)$, indicating an interaction between the reagents.

\section{DSC}

Figure 2 shows the DSC curves of NOR (a), RIB (b), and cocrystal (c). In the DSC curve of the NOR (Fig. 2a), an endothermic event is observed in the range of $75-110{ }^{\circ} \mathrm{C}$

Table 1 Temperature ranges $\left(\theta^{\circ} \mathrm{C}\right)$, mass loss $(\Delta m)$, and peak temperature $\left(T_{\mathrm{P}}\right)$ observed at each step in the TG/DTG-DTA curves of NOR, RIB, and NOR-RIB 1:1 TG/DTG-DTA curves

\begin{tabular}{|c|c|c|c|c|}
\hline Material & $\begin{array}{l}1 \text { st } \\
\text { Step }\end{array}$ & $\begin{array}{l}\text { 2nd } \\
\text { Step }\end{array}$ & 3rd Step & 4th Step \\
\hline \multicolumn{5}{|l|}{ NOR } \\
\hline$\theta /{ }^{\circ} \mathrm{C}$ & & & $393-467$ & $467-790$ \\
\hline$\Delta m / \%$ & 3.48 & 29.19 & 11.57 & 55.76 \\
\hline$T_{\mathrm{P}} /{ }^{\circ} \mathrm{C}$ & - & $377 \uparrow$ & - & $647 \uparrow$ \\
\hline \multicolumn{5}{|l|}{ RIB } \\
\hline$\theta /{ }^{\circ} \mathrm{C}$ & $260-398$ & & $398-760$ & - \\
\hline$\Delta m / \%$ & 46 & & 54 & - \\
\hline$T_{\mathrm{P}} /{ }^{\circ} \mathrm{C}$ & $(299-401)^{*}$ & & $554 \uparrow$ & - \\
\hline \multicolumn{5}{|c|}{ NOR-RIB 1:1 } \\
\hline$\theta /{ }^{\circ} \mathrm{C}$ & $35-125$ & $200-292$ & $29-380$ & $380-760$ \\
\hline$\Delta m / \%$ & 4.62 & 11.13 & 25.30 & 58.95 \\
\hline$T_{\mathrm{P}} /{ }^{\circ} \mathrm{C}$ & - & - & - & $553 \uparrow$ \\
\hline
\end{tabular}

$\downarrow$ Endothermic peak; $\uparrow$ exothermic peak; *exotherm

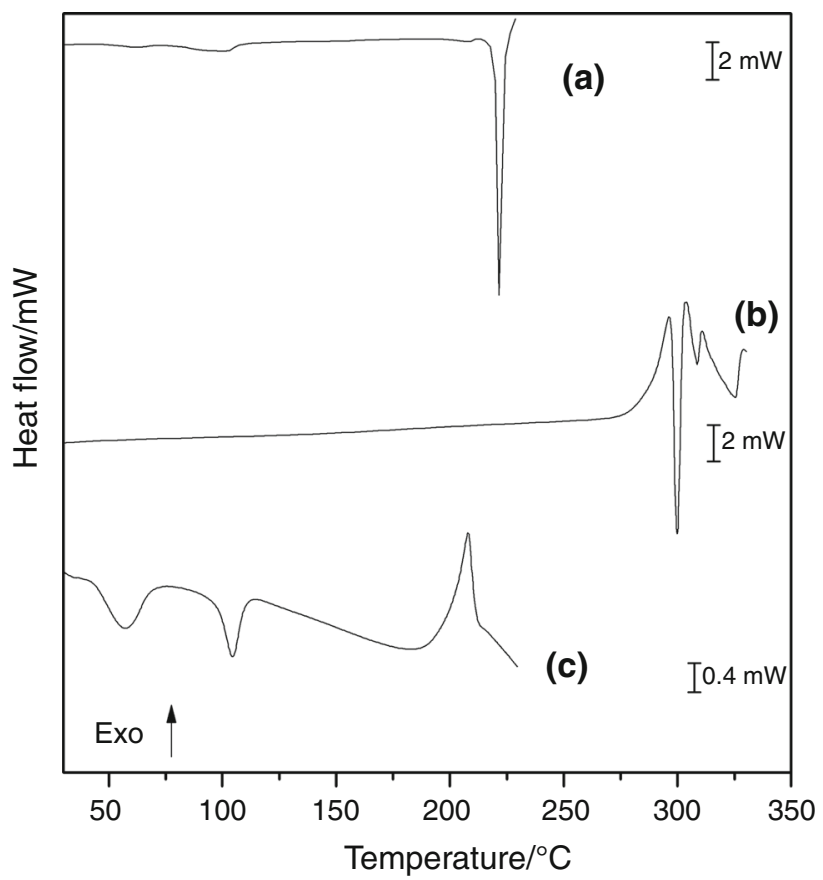

Fig. 2 DSC curves of a NOR, b RIB, and c cocrystal

referring to water vaporization $\left(\Delta H=28.3 \mathrm{~J} \mathrm{~g}^{-1}\right)$, which agrees with the data of the TG-DTA curves (Fig. 1a) and with Salceanu et al. [20], who describe that this event occurs due to NOR dehydration. A sharp peak at $221{ }^{\circ} \mathrm{C}$ is also observed for the NOR melt $\left(\Delta H_{\text {melting }}=128.2 \mathrm{~J} \mathrm{~g}^{-1}\right)$.

In the DSC curve of the RIB (Fig. 2b), some overlapped endothermic and exothermic events were observed, in the range of $270-325{ }^{\circ} \mathrm{C}$ that are related to decomposition/ oxidation of organic matter and melting of the decomposed product. The melting peak temperature is about $304{ }^{\circ} \mathrm{C}$; however, it is not possible to calculate the enthalpy event due to overlapped events. The data obtained in the present work disagree with the references [15-18]. According to Sheraz et al. [16], the RIB melts at approximately $280{ }^{\circ} \mathrm{C}$ followed by decomposition. Moffat reports that the RIB starts a darkening process from $240{ }^{\circ} \mathrm{C}$ and melting at 278-282 ${ }^{\circ} \mathrm{C}$, followed by decomposition [15]. In the DSC curve of the cocrystal (Fig. 2c), the two large endothermic peaks correspond to the evaporation of water/chloroform solvents at $81{ }^{\circ} \mathrm{C} \quad\left(\Delta H=43.2 \mathrm{~J} \mathrm{~g}^{-1}\right)$ and $111^{\circ} \mathrm{C}$ $\left(\Delta H=26.7 \mathrm{~J} \mathrm{~g}^{-1}\right)$. An exothermic peak at $207^{\circ} \mathrm{C}$ $\left(\Delta H=82.8 \mathrm{~J} \mathrm{~g}^{-1}\right)$ is attributed to the decomposition of organic matter.

The DSC curve of the NOR/RIB 1:1 blend did not show API and coformer melting peaks, and a decrease in thermal stability is still observed. Thus, it was evident that the mechanochemical synthesis promoted an interaction 

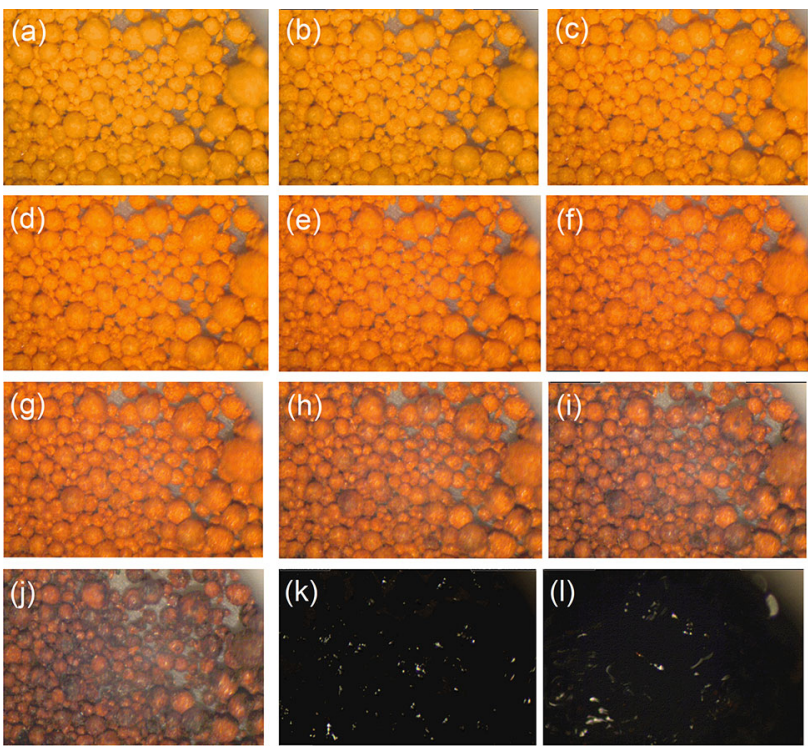

Fig. 3 Photo-DSC of pure RIB. Images obtained at temperatures of a $25{ }^{\circ} \mathrm{C}$, b $50{ }^{\circ} \mathrm{C}$, c $100{ }^{\circ} \mathrm{C}$, d $150{ }^{\circ} \mathrm{C}$, e $200{ }^{\circ} \mathrm{C}$, f $250{ }^{\circ} \mathrm{C}$, i $290{ }^{\circ} \mathrm{C}$, j $295{ }^{\circ} \mathrm{C}$, k $300{ }^{\circ} \mathrm{C}$, and $\mathbf{l} 310{ }^{\circ} \mathrm{C}$

between the API and the coformer agent, which suggests the formation of a cocrystal.

\section{DSC-photovisual}

Figure 3 shows the images obtained by photo-DSC from RIB (Video S-1). The constant change in RIB coloration from yellow to orange during heating, in the range of $50-140{ }^{\circ} \mathrm{C}$ (Fig. 3a-d), may be due to the loss of surface water in the sample.

The RIB initiates a more pronounced decomposition process after $250{ }^{\circ} \mathrm{C}$ (Fig. $\left.3 \mathrm{j}-1\right)$, and at $304{ }^{\circ} \mathrm{C}$ the product of the decomposition melts, which agrees with the observations of the TG/DTG-DTA and DSC curves of RIB. The same behavior was observed in $\mathrm{N}_{2}$ atmosphere (DSC curve S-2 and Video S-3).

Photographs obtained in the photo-DSC system of the cocrystal (Video S-4) are presented in Fig. 4. At $170{ }^{\circ} \mathrm{C}$ (Fig. $4 \mathrm{e}-\mathrm{g}$ ), the sample began to darken, which is attributed to a decomposition process and associated with the exothermic event at $200{ }^{\circ} \mathrm{C}$ in the DSC curve (Fig. 2c).

The melting event is not observed in the cocrystal (Fig. $4 \mathrm{~g}-\mathrm{i}$ ), and at $200{ }^{\circ} \mathrm{C}$ the mass loss of the decomposition process begins.

\section{DRX}

Comparing the X-ray diffractograms in Fig. S-5, there was partial amorphization of the sample, due to the grinding process, and there were changes in the orientation
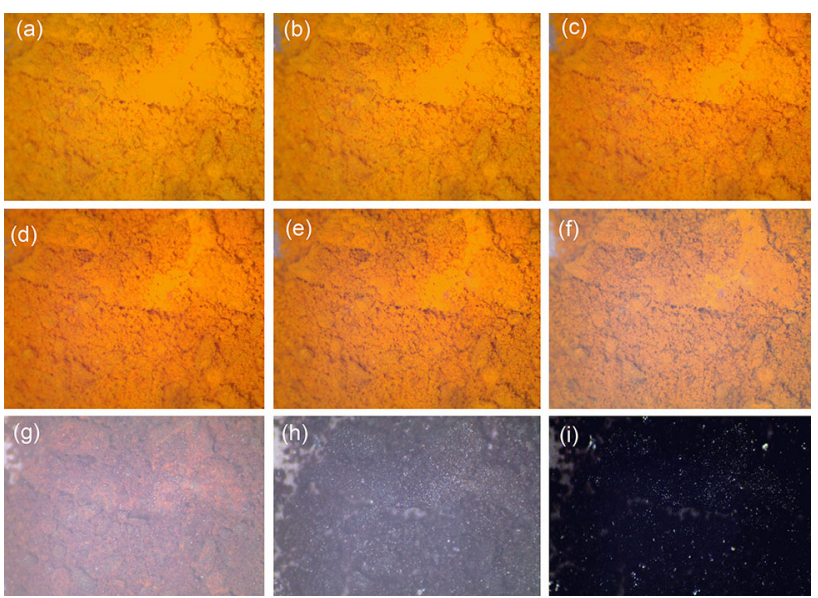

Fig. 4 Photo-DSC of the cocrystal. Images obtained at temperatures of a $25{ }^{\circ} \mathrm{C}$, b $57{ }^{\circ} \mathrm{C}$, c $105^{\circ} \mathrm{C}$, d $150{ }^{\circ} \mathrm{C}$, e $170{ }^{\circ} \mathrm{C}$, f $200{ }^{\circ} \mathrm{C}$, g $208{ }^{\circ} \mathrm{C}$, h $213{ }^{\circ} \mathrm{C}$, i and $220^{\circ} \mathrm{C}$

preferences. However, the grinding did not cause changes in the crystalline structure of the ground compound in relation to pure NOR (without grinding). This means that

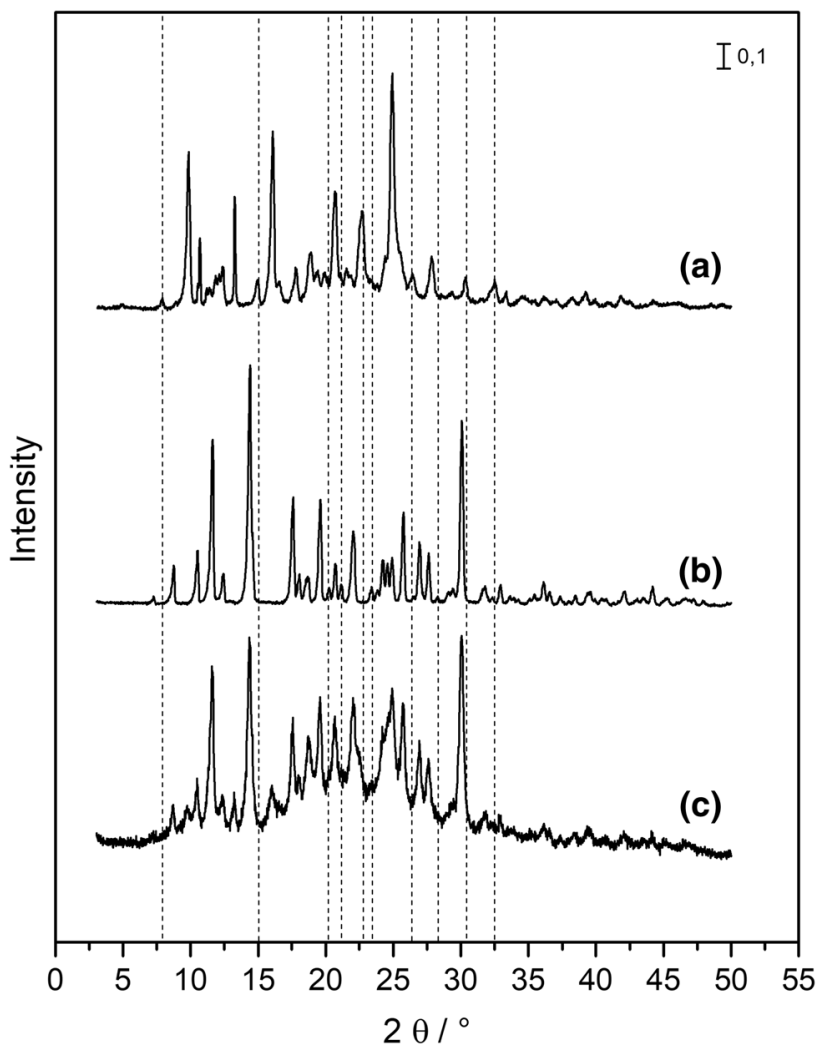

Fig. 5 X-ray diffractograms by the powder method of a NOR, b RIB, and c cocrystal 


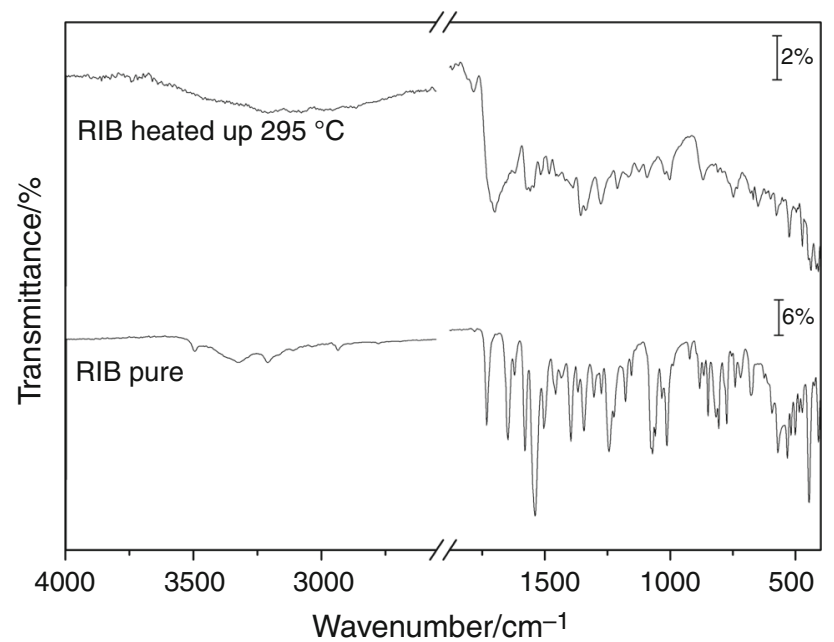

Fig. 6 Absorption spectra in the infrared region of the RIB heated to $295{ }^{\circ} \mathrm{C}$ and the pure RIB

the NOR did not undergo polymorphic transition during the grinding process under the conditions adopted. The same behavior was observed in the diffractogram of the RIB (Fig. S-6), with no polymorphic transition due to the mechanochemical process.

The diffractogram of the NOR-RIB 1:1 mechanochemical synthesis product (Fig. 5-c) shows the disappearance of the peaks at $7.9^{\circ} ; 14.9^{\circ} ; 20.3^{\circ} ; 21.2^{\circ} ; 22.8^{\circ} ; 23.4^{\circ}$; $26.4^{\circ} ; 28.3^{\circ} ; 30.3^{\circ}$; and $32.5^{\circ}$, as observed by the dashed lines shown in Fig. 5. Therefore, a new diffraction pattern was observed, which proves the formation of a cocrystal. Due to the difference in solubility between the reactants, it was not possible to obtain the monocrystal [21, 22].

\section{MIR}

Figure $6 \mathrm{a}-\mathrm{b}$ shows the MIR of the RIB heated at $295{ }^{\circ} \mathrm{C}$ and the RIB at room temperature. The spectra are different, which indicate changes in the absorption bands. The spectra contain $\mathrm{CO}$ stretch of primary alcohol at $1068 \mathrm{~cm}^{-1}$ and secondary alcohols at $1012 \mathrm{~cm}^{-1}$, and $\mathrm{NH}$ and $\mathrm{OH}$ stretches at $3496 \mathrm{~cm}^{-1}$ and $3325 \mathrm{~cm}^{-1}$, symmetrical and asymmetric stretching of $\mathrm{C}=\mathrm{O}$ at $1653 \mathrm{~cm}^{-1}$ and $1733 \mathrm{~cm}^{-1}$, which are characteristic bands of the RIB $[23,24]$, thus confirming that the melting of the compound at $304{ }^{\circ} \mathrm{C}$ (endo DSC event Fig. 2-b) is an intermediate thermal decomposition.

Figure 7 shows the absorption spectra in the infrared region of NOR, RIB, and cocrystal. Figure 7-a presents the

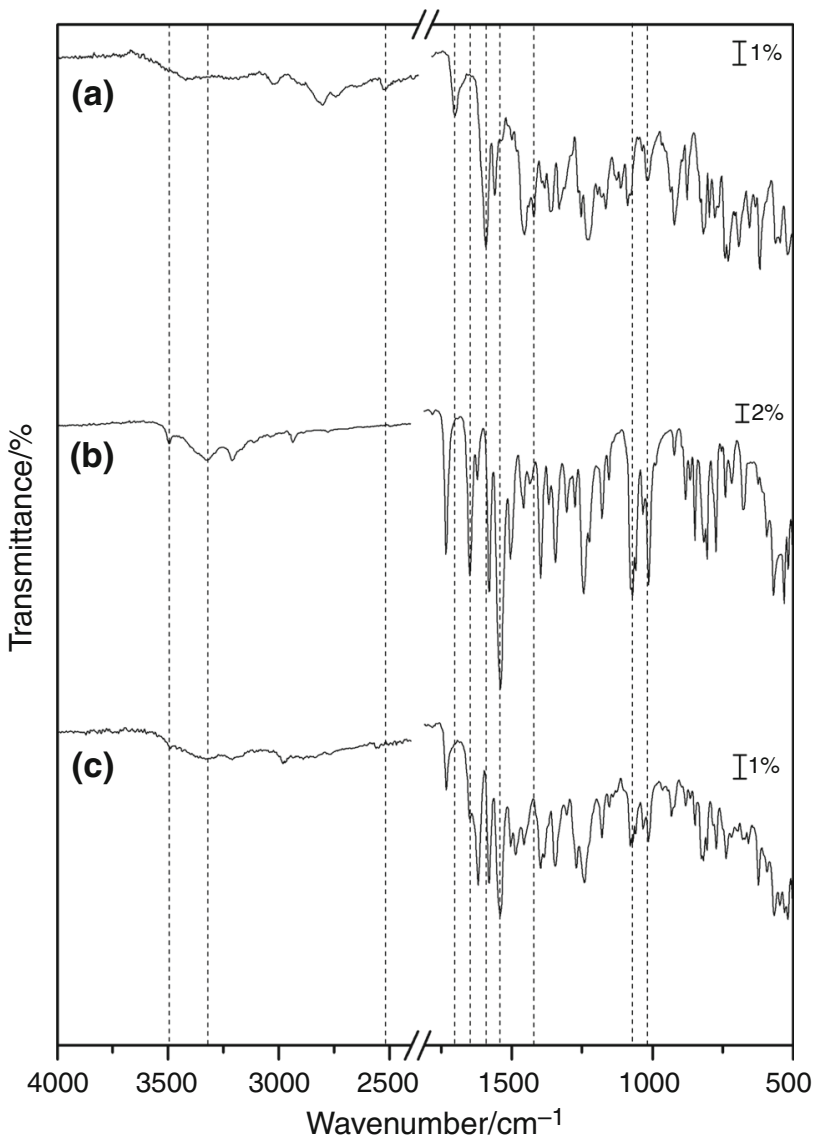

Fig. 7 Absorption spectra in the infrared region a NOR, b RIB, and c cocrystal

NOR $\mathrm{C}=\mathrm{O}$ bands of carboxylic acid at $1724 \mathrm{~cm}^{-1}$, carboxylate ion at $1614 \mathrm{~cm}^{-1}$ (asymmetric axial deformation) and $1440 \mathrm{~cm}^{-1}$ (symmetrical axial deformation), and protonation of the piperazine at $2550 \mathrm{~cm}^{-1}[25,26]$. The RIB bands are (Fig. 7-b) NH stretching at $3494 \mathrm{~cm}^{-1}, \mathrm{OH}$ stretching at $3326 \mathrm{~cm}^{-1}$, symmetrical and asymmetric stretches of the carbonils at $1647 \mathrm{~cm}^{-1}$, axial deformation of the $\mathrm{C}=\mathrm{O}$ bond of the lactam at $1539 \mathrm{~cm}^{-1}$, and the primary and secondary alcohols at $1070 \mathrm{~cm}^{-1}$ and $1014 \mathrm{~cm}^{-1}$, respectively.

The aforementioned bands are not present in the absorption spectrum in the infrared region of the cocrystal (Fig. 7c). It is therefore believed that NOR and RIB interacted through these functional groups forming a multicomponent crystalline solid, i.e., a cocrystal. Figure 8 shows a proposal for the interaction between API and coformer in the formation of the NOR-RIB 1:1 cocrystal. 
<smiles>CCn1cc(C(=O)O[C@@H](O)CO)c(=O)c2cc(F)c(N3CC[NH+](C(=O)O[C@@H](O)CO)CC3)cc21</smiles>

Fig. 8 Proposal of interaction between API and coformer in the formation of the NOR-RIB 1:1 cocrystal

\section{Conclusions}

Riboflavin presented a thermal behavior different from that reported in the literature. Photo-DSC images show the darkening process of the sample, and TG/DTG-DTA curves show mass loss and thermal decomposition before fusion of the decomposition product at $304{ }^{\circ} \mathrm{C}$. The MIR indicated that after the sample darkens, it presents a different spectrum from the RIB.

The mechanochemical method made it possible to obtain the norfloxacin cocrystal with Riboflavin in the molar ratio of $1: 1$. The thermoanalytical techniques, TG/ DTG-DTA, were fundamental to characterize the compound and provided evidence of the interaction between the API and the coformer. The synthesis product resulted in a cocrystal with lower thermal stability, which decomposes after $200{ }^{\circ} \mathrm{C}$ and does not melt. X-ray diffraction confirmed the formation of the cocrystal with a new diffraction pattern. The MIR spectra showed that the NOR interacts with the protonated pyridine and carboxylic ion with the RIB alcohols and lactam groups to form the cocrystal.

Acknowledgements The authors thank CAPES (proc. 024/2012 Proequipment), POSMAT/UNESP, and FAPESP (Processes: 2013/09022-7, 2017/08820-8, and 2018/03460-6) for financial support.

\section{References}

1. Morissette SL, Almarsson Ö, Peterson ML, et al. High-throughput crystallization: polymorphs, salts, co-crystals and solvates of pharmaceutical solids. Adv Drug Deliv Rev. 2004;56:275-300.

2. Hilfiker R, Blatter F, Raumer MV. Relevance of solid-state properties for pharmaceutical products. In: Hilfiker R, editor. Polymorphism: in the pharmaceutical industry. London: WileyVCH; 2006. p. 1-19.

3. Cristofoletti R, Chiann C, Dressman JB, et al. A comparative analysis of biopharmaceutics classification system and biopharmaceutics drug disposition classification system: a cross-sectional survey with 500 bioequivalence studies. J Pharm Sci. 2013;102:3136-44.

4. Dezani AB, Pereira TM, Caffaro AM, et al. Determination of lamivudine and zidovudine permeability using a different ex vivo method in Franz cells. J Pharmacol Toxicol Methods. 2013;67:194-202.

5. Gomes TA, Costa SPM, Medeiros GCR, et al. Estratégias utilizadas para o incremento da solubilidade do fármaco antiretroviral classe II: Efavirenz. J Basic Appl Pharm Sci. 2015;36:239-49.

6. Douroumis D, Ross SA, Nokhodchi A. Advanced methodologies for cocrystal synthesis. Adv Drug Deliv Rev. 2017;117:178-95.

7. Wang N, Xie C, Lu H et al. Cocrystal and its application in the field of active pharmaceutical ingredients and food ingredients. Curr Pharm Des. 2018.

8. Kuminek G, Cao F, de Oliveira Bahia, da Rocha A, et al. Cocrystals to facilitate delivery of poorly soluble compounds beyond-rule-of-5. Adv Drug Deliv Rev. 2016;101:143-66.

9. Prado LD, Rocha HVA. Estado Sólido na Indústria Farmacêutica: Uma Breve Revisão. Rev Virtual Quim. 2015;7:2080-112.

10. Perpétuo GL, Chierice GO, Ferreira LT, et al. A combined approach using differential scanning calorimetry with polarized light thermomicroscopy in the investigation of ketoprofen and nicotinamide cocrystal. Thermochim Acta. 2017;651:1-10. 
11. Shan N, Toda F, Jones W. Mechanochemistry and co-crystal formation: effect of solvent on reaction kinetics. ChemComm. 2002;20:2372-3.

12. Li S, Yu T, Tian Y, et al. Synthesis of Pharmaceutical cocrystal suspensions via hot melt extrusion: feasibility studies and physicochemical characterization. Mol Pharm. 2016;13:3054-68.

13. Ferreira LT, Holanda BBC, Alarcon RT, et al. Estudo térmico, caracterização espectroscópica e difração de raios x do cocristal de ácido salicílico com ácido nicotínico obtido por síntese mecanoquímica. Braz J Therm Anal. 2017;6:7-11.

14. Breda SA, Jimenez-Kairuz AF, Manzo RH, et al. Solubility behavior and biopharmaceutical classification of novel high-solubility ciprofloxacin and norfloxacin pharmaceutical derivatives. Int J Pharm. 2009;371:106-13.

15. Moffat AC, Osselton MD, Widdop B, et al. Clarke's analysis of drugs and poisons. 4th ed. London: Pharmaceutical Press; 2017. p. 2017.

16. Sheraz MA, Kazi SH, Ahmed S, et al. Photo, thermal and chemical degradation of riboflavin. Beilstein J Org Chem. 2014;10:1999-2012.

17. De Leenheer AP, Lambert WE, Bocxlaer JFV. Modern chromatographic analysis of vitamins: revised and expanded. 3rd ed. New York: Marcel Dekker; 2000. p. 402.

18. Masłowska J, Malicka M. Thermal behaviour of riboflavin. J Therm Anal Calorim 1988;34:3-9.
19. Kulla $\mathrm{H}$, Greiser $\mathrm{S}$, Benemann $\mathrm{S}$, et al. In situ investigation of a self-accelerated cocrystal formation by grinding pyrazinamide with oxalic acid. Molecules. 2016;21:917-1005.

20. Salceanu DC, Pincu E, Bruni G, et al. Physico-chemical study of norfloxacin and metronidazole binary mixtures. J Therm Anal Calorim. 2018;132:1095-103.

21. Basavoju S, Bostrom D, Velaga SP, Sitaram P. Pharmaceutical cocrystal and salts of norfloxacin. Cryst Growth Des. 2006;6:2699-708.

22. Al-Shammary FJ, Zubair MU, Mian MS, et al. Analytical profile of riboflavin. In: Brittain HG, editor. Analytical profiles of drug substances. London: Academic Press; 1990. p. 429-76.

23. Silverstein RM, Webster FX, Kiemle DJ. Identificação espectrométrica de compostos orgânicos. 7th ed. LTC Editora; 2006.

24. Karthikeyan S. Spectroscopic study of characterisation of commercial drug and its mixture. Proc Indian Natn Sci Acad. 2013;79:357-63.

25. Pavia DL, Lampman GM, Kriz GS, et al. Introdução à Espectroscopia. 4th ed. São Paulo: Cengage Learning; 2012.

26. Sahoo S, Chakraborti CK, Behera PK, et al. FTIR and Raman spectroscopic investigations of a Norfloxacin/Carbopol934 Polymerie suspension. J Young Pharm. 2012;4:138-45. 